\title{
Variabilidade patogênica e efeito de carboidratos no crescimento micelial, esporulação e agressividade de Colletotrichum gloeosporioides da pupunheira
}

\author{
Rudimar Mafacioli ${ }^{1}$, Dauri José Tessmann ${ }^{1,3}$, Álvaro Figueredo dos Santos ${ }^{2,3}$, João Batista Vida ${ }^{1}$
}

${ }^{1}$ Universidade Estadual de Maringá, Departamento de Agronomia, CEP 87020-900, Maringá, PR; Trabalho referente à Dissertação de Mestrado do primeiro autor. ${ }^{2}$ Embrapa Florestas, Estrada da Ribeira, Km 111, CEP 83411-000, Colombo, PR. ${ }^{3}$ Bolsista do CNPq.

Autor para correspondência: Dauri José Tessmann

Data de chegada:26/09/2005. Aceito para publicação em: 08/06/2007

\section{RESUMO}

Mafacioli, R.; Tessmann, D. J.; Santos, A. F.; Vida, J. B. Variabilidade patogênica e efeito de carboidratos no crescimento micelial, esporulação e agressividade de Colletotrichum gloeosporioides da pupunheira. Summa Phytopathologica, v.34, n.1, p.18-21, 2008

A agressividade de 17 isolados de Colletotrichum gloeosporioides associados à antracnose em folhas da pupunheira (Bactris gasipaes), oriundos de estados no Norte, Sudeste e Sul do Brasil, foi avaliada através de bioensaio com folhas de pupunheira destacadas, em três estágios de desenvolvimento: jovem, intermediária e completamente expandida. Diferenças significativas na agressividade dos isolados foram verificadas apenas em folhas completamente expandidas e intermediárias. O emprego de diferentes carboidratos, tais como glicose, maltose ou amido, em suplemento ao meio batata-ágar, influenciou o crescimento micelial e a esporulação de alguns isolados. A agressividade de dois isolados, dentre cinco isolados testados, foi significativamente maior quando os conídios foram produzidos no meio de cultura com amido, em relação aos meios com glicose e maltose.

Palavras chave: antracnose, Bactris gasipaes, fontes de carboidratos, patogenicidade, pupunha.

\section{ABSTRACT}

Mafacioli, R; Tessmann, D. J.; Santos, A. F.; Vida, J. B. Pathogenic variability and effect of carbohydrates on mycelial growth, sporulation and aggressiveness of Colletotrichum gloeosporioides from peach palm. Summa Phytopathologica, v.34, n.1, p.18-21, 2008

The aggressiveness of 17 Colletotrichum gloeosporioides isolates associated with anthracnose on leaves of peach palm (Bactris gasiapes) from Northern, Southeastern and Southern States of Brazil was evaluated through a bioassay using detached leaves of peach palm, at three stages: young, intermediate and fully expanded leaves. Differences on aggressiveness among isolates were significant only on fully expanded and intermediate leaves. Different sources of carbohydrates such as glucose, maltose and starch, added to potatoagar medium affected mycelial growth and sporulation of some isolates. Among five isolates tested, only two had their aggressiveness increased when conidia were produced on potato-agar medium supplemented with starch.

Additional keywords: anthracnose, Bactris gasipaes, carbohidrate sources, pathogenicity.

Em decorrência da expansão do cultivo da pupunheira (Bactris gasipaes Kunth) para a produção de palmito no Brasil, ocorrida nas últimas duas décadas, aumentou a importância da antracnose causada pelo fungo Colletotrichum gloeosporioides (Penz.) Penz. \& Sacc. A doença provoca danos principalmente em mudas e plantios de até um ano de idade, causando necrose foliar e morte das plantas (14). Em plantas adultas, a antracnose também causa podridão em frutos e prejudica a produção de sementes viáveis $(12,15)$.

A antracnose da pupunheira foi relatada pela primeira vez, no Brasil, no Estado do Amazonas em 1983 (4). Mais recentemente, a identificação do agente causal da doença foi confirmada por Mafacioli (11), com base no exame de amostras folhas com sintomas de doença e na patogenicidade de isolados oriundos da região Amazônica, onde a planta é nativa, e de estados do Sudeste e Sul do Brasil.

Colletotrichum gloeosporioides é um dos mais importantes patógenos de plantas de regiões tropicais e subtropicais do mundo (7). A ocorrência de variabilidade patogênica nessa espécie é conhecida em algumas hospedeiras $(1,3,6,8,9,10)$, o que sugere a hipótese de ocorrência de variabilidade patogênica também dentre isolados de $C$. gloeosporioides associados à antracnose da pupunheira. Tais conhecimentos em relação à amplitude da variabilidade patogênica de um fungo são importantes para o melhor entendimento da etiologia das doenças causadas por esse fungo e ao desenvolvimento de medidas de controle.

Estudos de variabilidade patogênica e de resistência genética requerem a padronização de metodologias de produção de esporos em culturas puras. Na literatura, há uma quantidade razoável de informações relacionadas à influência dos meios de cultura na produção de esporos de $C$. gloeosporioides $(3,5,7,8)$. No entanto, há pouca informação sobre a influência dos meios de cultura na qualidade fisiológica de esporos utilizados como inóculo (5).

O objetivo principal deste trabalho foi analisar a variabilidade patogênica de isolados de $C$. gloeosporioides, procedentes de diversas regiões do Brasil, em folhas de pupunheira destacadas, em três fases de desenvolvimento: jovem, intermediária e completamente expandida. O objetivo adicional foi avaliar o efeito nutricional de fontes suplementares de carboidratos ao meio batata-ágar, no crescimento micelial, esporulação e agressividade de isolados do patógeno. 


\section{MATERIAL E MÉTODOS}

Os ensaios foram realizados no Laboratório de Fitopatologia da Universidade Estadual de Maringá, PR. Dezessete isolados de $C$. gloeosporioides foram obtidos de folhas da pupunheira com sintomas de antracnose, procedentes de diversas regiões do Brasil (Tabela 1). Culturas puras dos isolados foram obtidas a partir de pontas de hifas e estão preservadas em tubos de ensaio contendo meio BatataDextrose-Ágar (BDA) com óleo mineral, à temperatura entre 5 a $10^{\circ} \mathrm{C}$.

A agressividade dos isolados foi comparada através de bioensaio com folhas destacadas de pupunheira, em três estádios de desenvolvimento: jovens, intermediárias e expandidas. As folhas foram coletadas de mudas que não sofreram aplicação de fungicidas.

Previamente à inoculação, as folhas foram lavadas em água corrente, desinfestadas com a imersão em álcool 70\% e em hipoclorito de sódio $0,5 \%$, por $1 \mathrm{~min}$. Em seguida, foram enxaguadas em água esterilizada, secas com papel toalha esterilizado e acondicionadas em placas de Petri com quatro discos de papel filtro umedecidos e esterilizados.

Conídios do patógeno foram produzidos em meio BDA, em placas de Petri mantidas a $22 \pm 2^{\circ} \mathrm{C}$ e fotoperíodo de $12 \mathrm{~h}$, por sete dias. Para o preparo da suspensão de esporos foram adicionados $10 \mathrm{~mL}$ de água destilada esterilizada às placas e, em seguida, fez-se a raspagem com alça de vidro. Essa suspensão foi filtrada em dupla camada de gaze.

Ensaios preliminares mostraram que, para o estabelecimento da doença, a inoculação deve ser feita com ferimentos nas folhas. A inoculação foi realizada depositando-se um disco de papel filtro de $10 \mathrm{~mm}$ de diâmetro, previamente embebido no inóculo, na concentração de $3,0 \times 10^{5}$ esporos por $\mathrm{mL}$, sobre quatro pontos em cada folha, com ferimentos causados artificialmente. Os ferimentos foram produzidos com auxílio de um conjunto de seis agulhas esterilizadas afixadas em rolha de cortiça e espaçadas de $5 \mathrm{~mm}$ entre si. Na testemunha, o disco de papel filtro foi embebido apenas em água destilada. As placas foram mantidas a $22 \pm 2^{\circ} \mathrm{C}$, com fotoperíodo de $12 \mathrm{~h}$.

A avaliação da agressividade dos isolados foi realizada no oitavo dia após a inoculação com base em uma escala de notas, onde: $0=$ ausência de necrose no local da inoculação; 1 = necrose do tecido no local da inoculação sem o coalescimento das manchas necróticas; 2 = necrose do tecido no local da inoculação com o coalescimento de até $50 \%$ das manchas necróticas; 3 = necrose do tecido no local da inoculação com o coalescimento de até $75 \%$ das manchas necróticas; 4 = necrose do tecido no local da inoculação com o coalescimento de $100 \%$ das manchas necróticas; 5 = coalescimento das manchas necróticas com a expansão da lesão nos tecidos adjacentes ao ponto de inoculação.

$\mathrm{O}$ delineamento experimental foi inteiramente casualizado, em arranjo fatorial, representado pelos isolados e idades das folhas, com quatro repetições por tratamento. As médias foram comparadas pelo teste de Scott-Knott, a 5\% de probabilidade. Os dados desse e dos demais ensaios foram analisados com programa SAEG (13).

Para a análise do efeito da nutrição com carboidratos sobre o crescimento micelial, esporulação e agressividade de $C$. gloeosporioides, foram utilizados os seguintes carboidratos como fontes de carbono: glicose (monossacarídeo), maltose (dissacarídeo) e amido (polissacarídeo). Foram adicionados $20 \mathrm{~g}$ de cada carboidrato separadamente ao meio batata-ágar (batata, 200g; ágar, 17g; água destilada, 1L), conforme a metodologia descrita por Assis et al. (5). Os meios, após autoclavagem, foram distribuídos em placas de Petri de $90 \mathrm{~mm}$ de diâmetro, na proporção de $20 \mathrm{~mL}$ por placa. Cinco isolados de C. gloeosporioides, cultivados em meio BDA por oito dias a $22 \pm 2^{\circ} \mathrm{C}$ e fotoperíodo de $12 \mathrm{~h}$, foram avaliados nos

Tabela 1. Origem e agressividade de isolados de Colletotrichum gloeosporioides agente de antracnose em folhas de pupunheira.

\begin{tabular}{|c|c|c|c|c|c|}
\hline \multirow[b]{2}{*}{ Isolados } & \multirow[b]{2}{*}{ Origem (Município/Estado) } & \multicolumn{4}{|c|}{ Agressividade $^{1}$} \\
\hline & & Folha expandida & Folha intermediária & Folha jovem & Média \\
\hline PGA-PR1 & Paranaguá (PR) & $2,75 \mathrm{Ab}^{2,3}$ & $2,25 \mathrm{Ab}$ & $1,50 \mathrm{Ba}$ & $2,16 \mathrm{a}$ \\
\hline PGA-PR2 & Paranaguá (PR) & $2,75 \mathrm{Ab}$ & $2,50 \mathrm{Ab}$ & $1,00 \mathrm{Ba}$ & $2,08 \mathrm{a}$ \\
\hline REG-SP2 & Registro (SP) & $2,50 \mathrm{Ab}$ & $2,75 \mathrm{Ab}$ & $1,50 \mathrm{Ba}$ & $2,25 \mathrm{a}$ \\
\hline PGA-PR3 & Paranaguá (PR) & $2,50 \mathrm{Ab}$ & $1,00 \mathrm{Ba}$ & $1,00 \mathrm{Ba}$ & $1,50 \mathrm{~b}$ \\
\hline PVE-RO3 & Porto Velho (RO) & $1,50 \mathrm{Aa}$ & $1,75 \mathrm{Ab}$ & $2,50 \mathrm{Aa}$ & $1,91 \mathrm{a}$ \\
\hline STO-PR3 & São Tomé (PR) & $1,50 \mathrm{Aa}$ & $1,50 \mathrm{Aa}$ & $1,50 \mathrm{Aa}$ & $1,50 \mathrm{~b}$ \\
\hline REG-SP1 & Registro (SP) & $1,50 \mathrm{Aa}$ & $2,00 \mathrm{Ab}$ & $1,00 \mathrm{Aa}$ & $1,50 \mathrm{~b}$ \\
\hline PVE-RO1 & Porto Velho (RO) & $1,50 \mathrm{Aa}$ & $1,25 \mathrm{Aa}$ & $1,25 \mathrm{Aa}$ & $1,75 \mathrm{~b}$ \\
\hline LIN-ES1 & Linhares (ES) & $1,50 \mathrm{Aa}$ & $1,25 \mathrm{Aa}$ & $1,00 \mathrm{Aa}$ & $1,25 \mathrm{~b}$ \\
\hline STO-PR2 & São Tomé (PR) & $1,25 \mathrm{Aa}$ & $1,50 \mathrm{Aa}$ & $1,25 \mathrm{Aa}$ & $1,75 \mathrm{~b}$ \\
\hline CGA-PR & Cidade Gaúcha (PR) & $1,25 \mathrm{Aa}$ & $1,00 \mathrm{Aa}$ & $1,00 \mathrm{Aa}$ & $1,08 \mathrm{~b}$ \\
\hline PGA-PR4 & Paranaguá (PR) & $1,25 \mathrm{Aa}$ & $1,00 \mathrm{Aa}$ & $1,00 \mathrm{Aa}$ & $1,08 \mathrm{~b}$ \\
\hline LIN-ES2 & Linhares (ES) & $1,25 \mathrm{Aa}$ & $1,00 \mathrm{Aa}$ & $1,00 \mathrm{Aa}$ & $1,08 \mathrm{~b}$ \\
\hline PVE-RO2 & Porto Velho (RO) & $1,00 \mathrm{Aa}$ & $1,50 \mathrm{Aa}$ & $1,50 \mathrm{Aa}$ & $1,75 \mathrm{~b}$ \\
\hline STO-PR 1 & São Tomé (PR) & $1,00 \mathrm{Aa}$ & $1,00 \mathrm{Aa}$ & $1,00 \mathrm{Aa}$ & $1,00 \mathrm{~b}$ \\
\hline RBR-AC1 & Rio Branco (AC) & $1,00 \mathrm{Aa}$ & $1,00 \mathrm{Aa}$ & $1,00 \mathrm{Aa}$ & $1,00 \mathrm{~b}$ \\
\hline RBR-AC2 & Rio Branco (AC) & $1,00 \mathrm{Aa}$ & $1,00 \mathrm{Aa}$ & $100 \mathrm{Aa}$ & $1,00 \mathrm{~b}$ \\
\hline Médias & & $1,59 \mathrm{~A}$ & $1,48 \mathrm{~A}$ & $1,23 \mathrm{~B}$ & \\
\hline
\end{tabular}

$\mathrm{CV}(\%)=14,8$

${ }_{2}^{1}$ Ensaio em folhas de pupunheira destacadas e inoculadas com ferimentos. As folhas inoculadas foram mantidas a $22 \pm 2^{\circ} \mathrm{C}$ e fotoperíodo de $12 \mathrm{~h}$.

2 Dados originais. Para efeito de análise, os dados de agressividade foram transformados em $(X+0,5)^{1 / 2}$.

${ }^{3}$ Médias seguidas de mesma letra maiúscula na horizontal e minúscula na vertical não diferem entre si pelo teste Scott-Knott, a 5\% de probabilidade. 
Tabela 2. Avaliação do crescimento micelial e esporulação de isolados de Colletotrichum gloeosporioides da pupunheira, em meio de batata-ágar suplementado com diferentes fontes de carboidratos.

\begin{tabular}{|c|c|c|c|c|c|c|}
\hline \multirow[t]{2}{*}{ Isolados } & \multicolumn{3}{|c|}{ Taxa de crescimento micelial $\left(\mathrm{mm} \mathrm{dia}^{-1}\right)$} & \multicolumn{3}{|c|}{ Esporulação $^{2}$} \\
\hline & Glicose & Maltose & Amido & Glicose & Maltose & Maltose \\
\hline CGA-PR & $8,0^{1} \mathrm{Aa}$ & 8,3 Aa & 8,6 Aa & $0,725 \mathrm{Aa}^{1,2}$ & $0,873 \mathrm{Aa}$ & $0,873 \mathrm{Aa}$ \\
\hline PGA-PR2 & $8,1 \mathrm{Aa}$ & $8,1 \mathrm{Aa}$ & $8,5 \mathrm{Aa}$ & $0,863 \mathrm{Aa}$ & $0,872 \mathrm{Aa}$ & $0,872 \mathrm{Aa}$ \\
\hline LIN-ES2 & $8,6 \mathrm{Aa}$ & $9,1 \mathrm{Aa}$ & $10,0 \mathrm{Bb}$ & $0,715 \mathrm{Aa}$ & $0,725 \mathrm{Aa}$ & $0,725 \mathrm{Aa}$ \\
\hline RBR-AC2 & $8,7 \mathrm{Aa}$ & $10,8 \mathrm{Bb}$ & 9,9 Bb & $0,724 \mathrm{Aa}$ & $0,716 \mathrm{Aa}$ & $0,716 \mathrm{Aa}$ \\
\hline PVE-RO3 & $9,5 \mathrm{Aa}$ & $10,0 \mathrm{Ab}$ & $9,8 \mathrm{Ab}$ & $0,707 \mathrm{Aa}$ & $0,718 \mathrm{Aa}$ & $0,718 \mathrm{Aa}$ \\
\hline CV (\%) & \multicolumn{3}{|c|}{7,2} & \multicolumn{3}{|c|}{14,0} \\
\hline
\end{tabular}

${ }_{2}^{1}$ Médias seguidas da mesma letra, maiúscula na linha e minúscula na coluna, não diferem entre si pelo teste de Scott-Knott a $5 \%$ de probabilidade.

Dados transformados para $(\mathrm{x}+0,5)^{1 / 2}$, onde $\mathrm{x}$ é a esporulação de $C$. gloeosporioides $\left(\mathrm{x} 10^{6}\right)$.

ensaios, fazendo-se a transferência de um disco da colônia, com diâmetro de $7 \mathrm{~mm}$, para o centro de cada placa de Petri contendo um carboidrato. Em seguida, as placas foram incubadas durante sete dias a $22 \pm 2^{\circ} \mathrm{C}$ e fotoperíodo de $12 \mathrm{~h}$. Ao final do sétimo dia de incubação, as placas foram avaliadas quanto à taxa média do crescimento micelial ( $\mathrm{mm} /$ dia), levando-se em consideração o diâmetro médio final, o qual foi obtido medindo-se dois pontos diametralmente opostos do perímetro da colônia, descontando-se $5 \mathrm{~mm}$ correspondentes ao disco de meio contendo o inóculo inicial do fungo.

A avaliação da esporulação dos isolados nos meios de cultura foi realizada após a avaliação do crescimento micelial. Para isso, uma suspensão de conídios foi preparada mediante a adição de $10 \mathrm{~mL}$ de água destilada esterilizada em cada placa, fazendo-se a remoção da superfície da colônia com o auxílio de uma alça de vidro. A suspensão de conídios foi filtrada em duas camadas de gaze e a concentração foi determinada em câmara de Neubauer.

Para a avaliação do efeito da nutrição de carboidratos na agressividade de isolados de C. gloeosporioides, foram preparadas suspensões de conídios de cinco isolados, à partir dos meios com os respectivos carboidratos, na concentração de $3,0 \times 10^{5}$ esporos por $\mathrm{mL}$, sendo a inoculação efetuada em folhas jovens de pupunheira. O processo de produção do inoculo, inoculação e avaliação foram os mesmos descritos anteriormente.

O delineamento experimental foi inteiramente casualizado, em arranjo fatorial, representados pelas fontes de carboidratos e isolados do patógeno, com três repetições por tratamento. As médias foram comparadas pelo teste de Scott-Knott, a 5\% de probabilidade.

\section{RESULTADOS E DISCUSSÃO}

Todos os isolados de C. gloeosporioides foram patogênicos à pupunheira e houve interação significativa entre os três estádios de folhas inoculadas e os isolados estudados $(\mathrm{Pd}=0.05)$. Os isolados apresentaram diferenças significativas de agressividade entre si em folhas completamente expandidas (maduras) e intermediárias $(\mathrm{P}=0,05)$ (Tabela 1). Nas folhas jovens, as diferenças de agressividade entre os isolados não foram significativas. De acordo com o agrupamento proporcionado pelo teste de Scott-Knott $(\mathrm{P}=0,05)$ com base na média de intensidade da doença nos três estádios de desenvolvimento das folhas, os isolados mais agressivos foram PGA-PR1, REG-SP2, PGAPR2 e PGA-RO3.

Na literatura, existem relatos de variabilidade patogênica de $C$. gloeosporioides em diversas hospedeiras, tais como Stylosanthes spp. $(6,9)$, seringueira (8), citros (3), Aeschynomene virginica (10) e cará (Dioscorea sp.) (1). Na pupunheira, verificou-se que as diferenças de agressividade dos isolados de C. gloeosporioides não foram muito acentuadas, muito embora tenham sido estatisticamente significativas. Verificou-se também que as folhas jovens da pupunheira foram menos afetadas pela antracnose do que as folhas maduras. Também nesse caso, as diferenças de intensidade da doença entre as folhas jovens e maduras não foram acentuadas. Esses resultados contradizem algumas observações de campo que mostram maior impacto da antracnose em plantas de pupunheira jovens. Possivelmente, os ferimentos causados pela abrasão de partículas de solo, transportadas pelo vento, nos tecidos das plantas, associados ao estresse resultante da exposição

Tabela 3. Agressividade ${ }^{1}$ de isolados de Colletotrichum gloeosporioides em folhas jovens de pupunheira inoculadas com conídios produzidos em meio de batata-ágar suplementado com diferentes fontes de carboidratos.

\begin{tabular}{lccc}
\hline Isolados & Fontes suplementares de carboidratos & Amido \\
\hline CGA-PR & Glicose & $2,50 \mathrm{Bb}$ & $3,50 \mathrm{Aa}$ \\
PGA-PR2 & $2,00 \mathrm{Ba}^{2,3}$ & $2,75 \mathrm{Ab}$ & $3,25 \mathrm{Aa}$ \\
LIN-ES2 & $1,50 \mathrm{Ba}$ & $2,00 \mathrm{Ab}$ & $2,50 \mathrm{Aa}$ \\
PVE-RO3 & $1,75 \mathrm{Aa}$ & $2,00 \mathrm{Ab}$ & $1,75 \mathrm{Ab}$ \\
RBR-AC2 & $2,50 \mathrm{Aa}$ & $1,50 \mathrm{Ab}$ & $\mathrm{Ab}$ \\
\hline
\end{tabular}

$\mathrm{CV}(\%)=15,4$

${ }_{1}^{1}$ Ensaio em folhas de pupunheira destacadas e inoculadas com ferimentos. As folhas inoculadas foram mantidas a $22 \pm 2^{\circ} \mathrm{C}$ e fotoperíodo de $12 \mathrm{~h}$.

${ }_{3}^{2}$ Dados originais. Para efeito de análise, os dados de agressividade foram transformados em $(\mathrm{X}+0,5)^{1 / 2}$.

${ }_{3}^{3}$ Médias seguidas da mesma letra maiúscula na linha e minúscula na coluna, não diferem entre si pelo teste Scott-Knott, a 5\% de probabilidade. 
excessiva ao vento e sol, sejam mais danosos às plantas jovens, predispondo-as à doença.

Com relação a nutrição de carboidratos no crescimento, esporulação e agressividade de $C$. gloeosporioides, a análise de variância evidenciou o efeito significativo da interação de isolados de C. gloeosporioides e meios de cultura com diferentes fontes de carboidratos $(\mathrm{P}=0,05)$. Diferenças significativas na taxa de crescimento micelial dos isolados foram verificadas apenas nos meios contendo maltose e amido, o mesmo não ocorrendo no meio com glicose. A produção de conídios foi significativamente maior no meio contendo amido apenas para dois isolados, CGA-PR e PGA-PR2, dentre os cinco isolados avaliados (Tabela 2). Do mesmo modo, para esses isolados, a suplementação com amido induziu o aumento significativo da sua agressividade em relação aos meios com glicose e maltose (Tabela 3).

Nos isolados de C. gloeosporioides da pupunheira estudados não houve a nítida diferenciação de colônias de crescimento lento ou rápido, tal como ocorre para isolados de C. gloeosporioides patogênicos ao cará (2) e citros (3). Os isolados que apresentaram as maiores taxas de crescimento micelial não foram os mesmos que produziram mais esporos. Tal resultado também foi observado por Assis et al (5). Esses autores verificaram que em C. gloeosporioides da mangueira o meio com amido favoreceu mais a esporulação dos isolados do que os meios com glicose e maltose. Também, observaram que os meios com glicose e maltose foram menos favoráveis à esporulação de $C$. gloeosporioides do que o meio com amido e, em concordância com esse estudo, o meio com amido exerceu maior efeito na indução da patogenicidade dos isolados.

Os resultados desse trabalho contribuíram para o maior conhecimento do patossistema pupunheira x C. gloeosporioides $\mathrm{e}$ para o desenvolvimento de metodologias de cultivo e produção de esporos do patógeno em culturas axênicas.

\section{REFERÊNCIAS BIBLIOGRÁFICAS}

1. Abang, M.M.; Fagbola, O.; Smalla, K.; Winter, S. Two genetically distinct populations of Colletotrichum gloeosporioides Penz. causing anthracnose disease of yam (Discorea spp.). Journal of Phytopathology, Berlim, v.153, n.3, p.137-142, 2005.

2. Abang, M.M.; Winter, S.; Mignouna, H.D.; Green, K.; Asiedu, R. Molecular taxonomic, epidemiological and population genetic approaches to understanding yam anthracnose disease. African Journal of Biotechnology, Nairobi, v.2, n.12, p.486-496, 2003.

3. Agostini, J.P.; Timmer, L.W.; Mitchell, D.J. Morphological and pathological characteristics of strains of Colletotrichum gloeosporioides from citrus. Phytopathology, Saint Paul, v.82, n.11, 13771382, 1992.

4. Alves, M.L.B.; Batista, M.F. Ocorrência de antracnose em pupunha (Bactris gasipaes H.B.K.) em Manaus. Acta Amazônica, Manaus, v.13, n.3/4, p.705, 1983.

5. Assis, T.C.; Menezes, M.; Andrade, D.E.G.T.; Coelho, R.S.B.; Oliveira, S.M.A. Estudo comparativo de isolados de Colletotrichum gloeosporioides quanto ao efeito da nutrição de carboidratos no crescimento, esporulação e patogenicidade em frutos de três variedades de mangueira. Summa Phytopathologica, Jaboticabal, v.27, n.2, p.208-212, 2001.

6. Chakraborty, S.; Perrott, R.; Ellis, N.; Thomas, M.R. New aggressive Colletotrichum gloeosporioides strains on Stylosanthes scabra detected by virulence and DNA analysis. Plant Disease, Saint Paul, v.83, n.4, p.333-340, 1998.

7. Freeman, S.; Katan, T.; Shabi, E. Characterization of Colletotrichum species responsible for anthracnose diseases of various fruits. Plant Disease, Saint Paul, v.82, n.2, p.596-604, 1998.

8. Furtado, E.L.; Bach, E.E.; Kimati, H.; Menten, J.O.M.; Silveira, A.P. Caracterização morfológica, patogênica e isoenzimática de isolados de Colletotrichum gloeosporioides de seringueira. Summa Phytopathologica, Jaboticabal, v.25, n.3, p.221-228, 1999.

9. Kelemu, S.; Skinner, D.Z.; Badel, J.L.; Moreno, C.X.; Rodriguez, M.X.; Fernandes, C.D.; Charchar, M.J.; Chakraborty, S. Genetic Diversity in South American Colletotrichum gloeosporioides isolates from Stylosanthes guianensis, a tropical forage legume. European Journal of Plant Pathology, Dordrecht, v.105, n.3, p.261-272, 1999.

10. Luo, Y.; TeBeest, D.O. Infection components of wild-type and mutant strains of Colletotrichum gloeosporioides f.sp. aeschynomene on northern jointvetch. Plant Disease, Saint Paul, v.81, n.4, p.404-409, 1997.

11. Mafacioli, R. Caracterização morfo-fisiológica e patogênica de isolados de Colletotrichum gloeosporioides da pupunheira (Bactris gasipaes). 2002. 80f. Dissertação (Mestrado em Agronomia) - Universidade Estadual de Maringá, Maringá.

12. Poltronieri, L.S.; Gasparoto, L.; Benchimol, R.L. Doenças da cultura da pupunheira. In: Duarte, M.L.R. Doenças de plantas no trópico úmido Brasileiro. I. Plantas industriais. Belém: Embrapa, 1999. p.209-217.

13. Ribeiro Jr., J.I. Análises Estatísticas no SAEG. Viçosa: Universidade Federal de Viçosa, 2001. 301p.

14. Santos, A.F.; Tessmann, D.J.; Nunes, W.M.C.; Vida, J.B.; Jaccoud Filho, D.S. Doenças foliares da pupunheira (Bactris gasipaes) no Estado do Paraná. Boletim de Pesquisa Florestal, Colombo, n.42, p.125-130, 2001

15. Vida, J B; Tessmann, D J; Mafacioli, R; Verzignassi, J R; Santos, A F. Colletotrichum gloeosporioides causando antracnose em frutos de pupunheira nos estados de Minas Gerais e Paraná. Summa Phytopathologica, Botucatu, v.32, n.4, p.384-385, 2006. 